\title{
A evolução do Sistema Automático de Catalogação de Conteúdo Audiovisual (SACCA)
}

\author{
Renato Luís de Souza Dutra * \\ Liane Margarida Rockenbach Tarouco ** \\ Mary Lucia Pedroso Konrath ${ }^{* * *}$ \\ Centro Interdisciplinar de Novas Tecnologias na Educação \\ Universidade Federal do Rio Grande do Sul \\ Brasil
}

\begin{abstract}
RESUMO
A crescente utilização de vídeos educacionais digitalizados no processo de ensino e aprendizagem ganhou importantes recursos com o surgimento de padrões que auxiliam descrevê-los e indexá-los de forma padronizada, tais como o MPEG 7, possibilitando a busca e seleção de vídeos ou partes dele. Com base nestas tecnologia buscou-se implementar um sistema que permita localizar por meio de palavras chave, segmentos de vídeos educacionais usando o apoio de um repositório de objetos de aprendizagem já em operação, o CESTA.
\end{abstract}

\section{Introdução}

Atualmente, as novas gerações vêm se formando através da linguagem audiovisual e o hábito de receber comunicação através da televisão vem reorganizando a forma de expressão de crianças e jovens. Orozco (1997) acrescenta que há pesquisas suficientes a partir das quais pode-se afirmar que as crianças aprendem muito mais rápido a partir dos diversos meios de comunicação, em especial da televisão, do que do professor na escola, e que se o que nossos alunos aprendem fora da aula é relevante para a sua aprendizagem, dentro da escola, é obrigação nossa, tomar em conta essa aprendizagem.

Neste sentido, há algum tempo videos são utilizados como ferramentas de apoio didático tanto na educação presencial como na educação a distância. Diversas iniciativas já produziram ou disponibilizaram diversos vídeos que podem ser utilizados para fins educacionais, tais como o Canal Futura (Fundação Roberto Marinho, 2004), o TV Escola do MEC (Secretaria de Educação a Distância, 2004), o Grupo de Trabalho de Vídeo Digital da RNP (GT VD, 2004) e o Projeto Colaboratorium da Secretaria de Ciência e Tecnologia do Rio Grande do Sul. Adicionalmente, diversas bibliotecas digitais começam a ser implementadas ao redor do mundo. Vídeos com conferências, aulas, experimentos, demonstração de procedimentos, visitas em campo etc... , resultando em acervo de vídeo que todavia tem uso aquém das expectativas/possibilidades, em decorrência do tempo demandado para que o acervo seja inspecionado pelos potenciais utilizadores, uma vez que a natureza da mídia, vídeo, não permite uma visualização rápida do conteúdo, implicando ao contrário, em assistir todo o vídeo para que se possa ter uma ideia de seu contúdo. Isto leva à sub-utilização de um material educacional que pode ter grande impacto no processo de aprendizagem.

Segundo Ferrés (1996) a linguagem audiovisual favorece a percepção acima da reflexão, a sensação sobre o conceito. Já conforme relatado por Santaella (1993), 75\% da percepção humana é visual, seguida da auditiva com $20 \%$, enquanto as outras modalidades somam juntas apenas $5 \%$ de

\footnotetext{
* Doutorando em Informática na Educação e Mestre em Ciência da Computação pela UFRGS

*** Doutora em Engenharia Elétrica pela USP, Mestre em Ciência da Computação pela UFRGS

**** Mestranda em Educação e Especialista em Informática na Educação pela UFRGS
} 
nossa capacidade perceptiva, argumento reforçado por Burmark (2004), segundo o qual estamos na idade das imagens e provavelmente a alfabetização primária do século 21 será visual.

Neste sentido é imprescindível que algumas providências sejam desencadeadas tais como:

- Investir na ampliação das videotecas existentes bem como tornar o acesso às mesmas mais facilitado.

- Buscar uma maior divulgação dos vídeos existentes

A utilização de vídeos educacionais no processo de ensino e aprendizagem ganhou importantes recursos com o surgimento de padrões, como o MPEG-7, que auxiliam descrevê-los de forma padronizada, possibilitando a busca e seleção de vídeos ou partes dele, tal como descrito em Tarouco(2003). A utilização das descrições MPEG-7, escritas em XML e integradas a um repositório de materiais audiovisuais, possibilitarão aos professores de forma simples e rápida, localizar vídeos educacionais adequados para o apoio em sala de aula. Adicionalmente servirá como ferramenta para que o aluno navegue, de forma hipertextual, nos diversos vídeos armazenados neste repositório.

Os sistemas de cadastramento existentes, tal como o do projeto CESTA - Coletânea de Entidades de Suporte ao uso da Tecnologia na Aprendizagem (CESTA 2004) para objetos de aprendizagem, ou o ALEPH, usado na biblioteca da UFRGS, usualmente se limitam a catalogar dados inerentes aos metadados. Perde-se nestas alternativas a possibilidade de indexação full-text que as máquinas de busca como Altavista e Google popularizaram e que são tão úteis e necessárias.

No âmbito da Internet 2 já foi iniciado um experimento com catalogação automática full content em que o áudio do vídeo é analisado e palavras chaves são identificadas e localizadas no tempo (em momento são faladas). Neste projeto, denominado VALA - Virtual Adaptative Learning Architecture, (VALA, 2004) é usado um software comercial VIRAGE, para fazer esta análise mas este software somente funciona para a língua inglesa. Todavia o resultado é muito relevante pois possibilita ao aluno digitar uma ou mais palavras chaves e receber uma coleção de URLs que apontam para vídeos armazenados no repositório (incluindo pontos específicos do vídeo onde a palavra é dita).

No projeto SACCA - Sistema Automático de Catalogação de Conteúdo Audiovisual, em desenvolvimento na Universidade Federal do Rio Grande do Sul, no Brasil, buscou-se um resultado similar mas operando inicialmente de forma não automática, porque não há no momento recursos (software de reconhecimento de áudio apropriado para o Português falado no Brasil).

\section{As iniciativas e acervos de vídeos no Brasil}

A preocupação com o uso de vídeo na educação ocorre desde o surgimento dos primeiros canais de televisão educativas. Desde aquela época a qualidade melhorou bastante, bem como a diversificação de seu uso e atualmente o vídeo educacional é utilizado tanto em cursos a distância como em material de apoio no ensino presencial.

No Brasil por iniciativa do MEC - Ministério de Educação e Cultura foi instituída a TV Escola que é um canal de televisão, via satélite, destinado exclusivamente à educação, iniciado em todo o Brasil em 4 de março de 1996. Seus principais objetivos são a capacitação, atualização, aperfeiçoamento e valorização dos professores da rede pública de Ensino Fundamental e Médio e o enriquecimento do processo de ensino-aprendizagem. O ponto de partida do Programa foi envio para escolas públicas com mais de 100 alunos de um televisor, um videocassete, uma antena parabólica, um receptor de satélite e um conjunto dez fitas de vídeo VHS, para iniciar as gravações. Há no Brasil, segundo o Censo de 2003, 60.955 escolas públicas com mais de 100 alunos. Nessas escolas, estudam 28.965.896 alunos e trabalham 1.091.661 professores. A TV Escola está em 39.634. o que representa $65 \%$ da rede pública brasileira. A TV Escola transmite dezessete horas de programação diária, com repetições, de forma a permitir às escolas diversas opções de horário para gravar os vídeos. 
Recentemente foi iniciado um processo de digitalização do acervo de vídeos que será colocado online ainda no ano de 2005. Isto representará uma quantidade apreciável de material que para ser apropriadamente utilizado precisa ser indexado de forma mais ampla e completa, demandando

Outro projeto na área de TV educativa é o Telecurso criado pela Fundação Roberto Marinho em 1978, visando inicialmente o $2^{\circ} \mathrm{Grau}$, transmitido na época por 60 emissoras de TV e 800 emissoras de rádio. Em 1995 o Telecurso 2o grau evoluiu para o Telecurso 2000, envolvendo o ensino fundamental, médio e profissionalizante e desde então vem despertando atenção de países como Estados Unidos, Argentina e Chile, sendo também atualmente utilizado no Timor Leste. No Telecurso o aluno pode estudar assistindo aos programas de TV transmitidos por diversas emissoras, assistir a fitas de vídeo gravadas e através do material impresso, podendo estudar em casa ou nas telessalas, onde podem contar com orientação de profissionais especializados.

Um outro projeto é o do canal Futura, um canal de televisão com a missão de "contribuir para a formação educacional da, possibilitar o acesso ao conhecimento e incentivar a cidadania e a participação pessoal" (FRM, 2004) . O Futura é uma iniciativa de diversas empresas, entre elas a Rede Globo, a CNN, a Fundação Itaú, a Votorantim entre outros. O Futura baseia-se em uma programação desenvolvida especialmente para servir de apoio a educação, onde os parceiros do projeto participam ativamente de sua gestão e diretrizes de programação, produzindo e divulgando programas e iniciativas na área social. O projeto conta também com uma mobilização comunitária que orienta as instituições de como utilizar os programas de maneira mais adequada.

Como se pode constatar pelas descrições apresentadas, começa a estar disponível uma grande quantidade e variedade de vídeos educacionais e junto com o crescente ganho de qualidade destas iniciativas brasileiras, ocorreram também importantes avanços no campo da tecnologia da informação e comunicação.

Com o surgimento da Internet, uma novo espectro de possibilidades foi aberto para uso deste acervo, diante da possibilidade da digitalização deste vídeos em formato streaming, possibilitando o acesso aos mesmos através da rede e ensejando a criação de grandes bibliotecas digitais. Entretanto para acompanhar este crescente aumento das bibliotecas digitais, faz-se necessário a catalogação e indexação dos vídeos para encontrar o conteúdo desejado, de forma rápida e dinâmica.

\section{Padrões de Indexação \& Ferramentas}

Neste contexto surgiram diversas iniciativas visando não só a catalogação de vídeos digitais, como também sua sincronização, indexação e descrição. Podemos citar entre estas iniciativas, o SMIL, o ANNODEX e o MPEG 7

\subsection{SMIL}

O SMIL (Synchronized Multimedia Integration Language), permite a criação de apresentações audiovisuais interativas (W3C, 2004). O SMIL é tipicamente utilizado para apresentações multimídia do tipo "rich media", que integram áudio e video streaming, texto ou qualquer outro tipo de arquivo. O SMIL é uma linguagem baseada no XML, trabalhando com tags semelhantes ao HTML, podendo ser editado por qualquer editor de texto comum, pois os elementos multimídia não são inseridos, somente referenciados. Com o SMIL é possível gerenciar a transmissão de arquivos multimídia por streaming, sincronizando estes arquivos com animações flash, páginas html, figuras, etc.

Devido a estes recursos de sincronização, o SMIL também possibilita que criar uma espécie de indexação destes arquivos de audio vídeo, através da sincronização das palavras chaves ou thumbnails, por exemplo ponto onde estas palavras ou imagens ocorrem. Outra grande vantagem do 


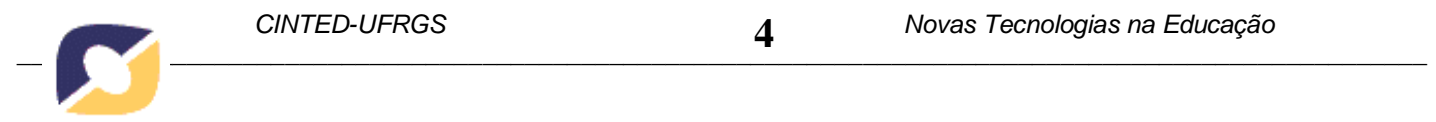

SMIL é sua utilização pelos dois dos mais importantes players multimídia do mercado, o Real Player e o Quicktime, garantindo portanto grande portabilidade destes materiais.

\subsection{ANNODEX - Annotation and Indexing}

O Annodex (Annodex, 2004), anotating and indexing, é uma especificação criada a partir do Continuous Media Project, iniciado na CSIRO (Australia's Commonwealth Scientific and Industrial Research Organisation), uma organização de pesquisa australiana envolvida nas mais diversas áreas. O Continuous Media Project foi iniciado por Silvia Pfeiffer em 2001, a partir das idéias contidas em um artigo de Bill Simpson-Young e Ken Yap em 1997, intitulado "An open continuous media environment on the Web".

Annodex possibilita a manipulação de arquivos de tempo-contínuo (áudio e vídeo) na Web. O formato Annodex, junto com o CMML (Continuous Media Markup Language), o Temporal URI Reference, servem de base para possibilitar a procura e navegação através de arquivos de tempocontinuo.

O Annodex permite a especificação de âncoras em bitstreams de tempo-contínuo, juntos com anotações textuais no formato de hiperlinks URI. Estas âncoras são anexadas sincronizadamente com os arquivos de tempo-contínuo, quando criadas no formato Annodex. Este formato permite a encapsulação de qualquer arquivo do tipo streaming, independentemente dos formatos de streaming. Adicionalmente, as tags XML escolhidas pelo Annodex, são semelhantes ao do XHTML, facilitando assim a vida dos desenvolvedores de conteúdos.

O principal objetivo do Annodex é permitir a integração de arquivos de tempo-contínuo dentro das funcionalidades de procura e navegação existente na Web.

\subsection{MPEG- 7}

O MPEG-7 é uma especificação padronizada desenvolvida pelo Moving Picture Experts Group, um grupo de trabalho da ISO/IEC criado em 1988, encarregado pelo desenvolvimento de padrões para representação codificada de áudio e vídeo digitais. O MPEG-7 descreve as características de conteúdos multimídia para que os usuários possam pesquisar e recuperar estes conteúdos de forma similar ao que ocorre nos mecanismos de busca na WWW. Para a criação destas descrições, o MPEG-7 disponibiliza um conjunto de elementos de metadados descritos em XML. Além das descrições textuais em arquivos XML, muitas vezes extensas, o MPEG-7 especifica descrições em formato binário, o BiM, permitindo o streaming e a compressão em até 98\% das descrições.

Diversos grupos de pesquisa e empresas do mercado, já estão pesquisando ferramentas que utilizem o MPEG-7 como linguagem padrão de descrição de vídeo. Entre ela podemos destacar o Ricoh MPEG-7 MovieTool utilizado para criar descrições, o Canon MPEG-7 Spoken Content Transcription Service um serviço que transcreve em XML no padrão MPEG-7 um arquivo de áudio e o IBM MPEG-7 Annotation Tool. IBM Annotation Tool é uma ferramenta desenvolvida pela Alphaworks da IBM, um grupo criado pela IBM para pesquisar novas tecnologias. Esta ferramenta visa dar suporte para descrever sequiências de vídeo gravadas no padrão de vídeo MPEG 1 e 2, através de metadados no padrão MEPG-7. Cada cena em uma sequência de video pode ser descrita com descrições estáticas, descrições de objetos chave, descrições de eventos e outras descrições léxicas. As descrições são associadas a cada cena e armazenadas como dados MPEG-7 em um arquivo XML.

O IBM Annotation Tool requer também um arquivo de segmentação, no qual a seqüência de vídeo é segmentada em pequenas unidades, chamadas de cenas. Este arquivo de segmentação pode ser carregado de outras fontes, como o "IBM CueVideo Shot Detection Tool Kit" ou segmentado automaticamente quando a ferramenta abre o arquivo de vídeo pela primeira vez. 


CINTED-UFRGS

\subsection{Qual a melhor especificação para ser aplicada na Educação ?}

As especificações descritas acima não são as únicas, nem as últimas voltadas para a descrição e anotação de vídeos digitais, mas coma base nelas conseguimos ter um espectro básico de opções disponíveis.

O MPEG 7 se destaca entre estes e os demais, por ser um padrão desenvolvido pela ISO e por ter sido criado especificamente com o intuito de descrever e indexar vídeos. $\mathrm{O}$ grande diferencial do MPEG-7 é sua abrangência, pois nele é possível fazer descrições que nos permitem indexar não somente palavras-chave em determinados intervalos do vídeo, como também permite a indexação por padrões de imagem, som e outros tipos de descrições. Desta maneira, podemos indexar um vídeo de tal forma que permita localizar quando determinado imagem, uma pessoa por exemplo, aparece no vídeo. O MPEG-7 pretende disponibilizar ferramentas para que a busca em imagens, vídeos e arquivos sonoros seja tão fácil quanto é a busca em textos.

A aplicação do MPEG-7 na educação pode ocorrer de diversas formas, podendo ser utilizado para permitir a busca de determinadas palavras em um vídeo que sejam interessantes para uma aula; encapsulando informações adicionais de determinadas cenas possibilitando a exploração pelos alunos; ou permitindo que alunos façam suas próprias anotações (gerando uma anotação MPEG-7) e observações em um determinado vídeo. Um exemplo é o VEL - Virtual Enterpreneurship Lab (VEL 2004), um ambiente virtual hipermídia para alunos de empreendedorismo, que permitem que os alunos pesquisem diferentes vídeos e informações relacionadas a eles através do padrão MPEG-7.

\section{Projeto SACCA}

Como descrito anteriormente, existem diversas iniciativas no âmbito da criação de conteúdo audiovisual com vistas a sua aplicação na educação. A digitalização destes materiais e a criação de bibliotecas digitais é uma tendência cada vez mais apoiada no meio acadêmico. No sentido de catalogar conteúdos foi desenvolvido anteriormente na UFRGS o Projeto CESTA, um repositório de objetos de aprendizagem que cataloga estes objetos seguindo o Learning Objetc Metadata (LOM), especificação da IEEE visando descrever conteúdos educacionais.

O SACCA (Sistema Automático de Catalogação de Conteúdo Audiovisual), é um projeto que visa complementar os esforços empreendidos no projeto CESTA, especificamente voltado para a catalogação de vídeos digitais (SACCA 2004). No presente projeto, pretende-se alcançar um resultado similar mas operando inicialmente de forma não automática, porque não há, no momento, software de reconhecimento de áudio apropriado para o Português falado no Brasil. Assim, busca-se projetar e desenvolver um sistema que apoie o processo de anotação e descrição full content, mas com a intermediação de um usuário que assiste ao vídeo e seleciona as palavras chave a serem associadas às cenas e incluídas na descrição. Para tanto, está sendo usado um software freeware, o IBM Annotation Tool, que permite descrever arquivo de vídeo gravado no formato de vídeo MPEG (1 e 2), gerando uma descrição XML segundo o padrão MPEG 7. Através deste o usuário pode anotar palavras agregando as informações de tempo de início em que as mesmas foram faladas 


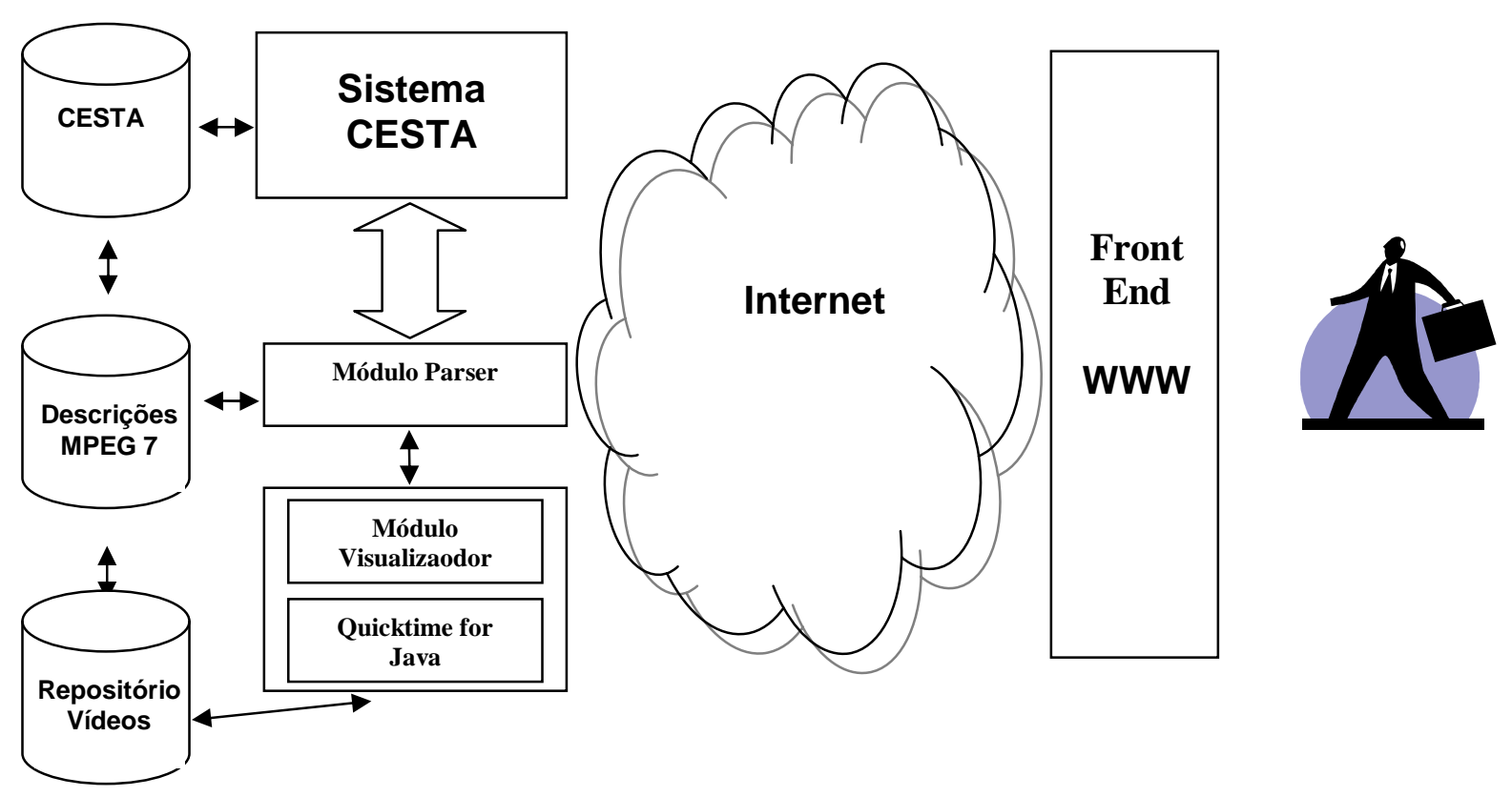

Figura 1 - Esquema geral do funcionamento do SACCA

O sistema sendo implementado faz o interfaceamento com este software e o sistema CESTA. As informações resultantes devidamente anotadas no arquivo XML padrão MPEG-7 são armazenadas em um banco de dados, com todas a palavras chave catalogadas e ponteiros para os arquivos XML (MPEG 7) e para os registros do projeto CESTA, onde os objetos de aprendizagem tipo vídeo também estão catalogados e onde estão as informações referentes aos demais metadados de catalogação.

Para que o SACCA armazene estes dados no banco de dados um Módulo Parser foi desenvolvido e agregado ao módulo de edição e catalogação do CESTA. Quando o usuário estiver editando um registro de um objeto de vídeo já cadastrado no CESTA, ficará disponível um botão para a anexação do XML contendo as descrições do vídeo. Este botão quando selecionado permitirá ao usuário localizar o arquivo XML na máquina local, carregando-o para o servidor do SACCA e ao mesmo tempo interpretando a árvore XML, para gerar o índice de palavras-chave do SACCA e os ponteiros para o vídeo e o XML. 


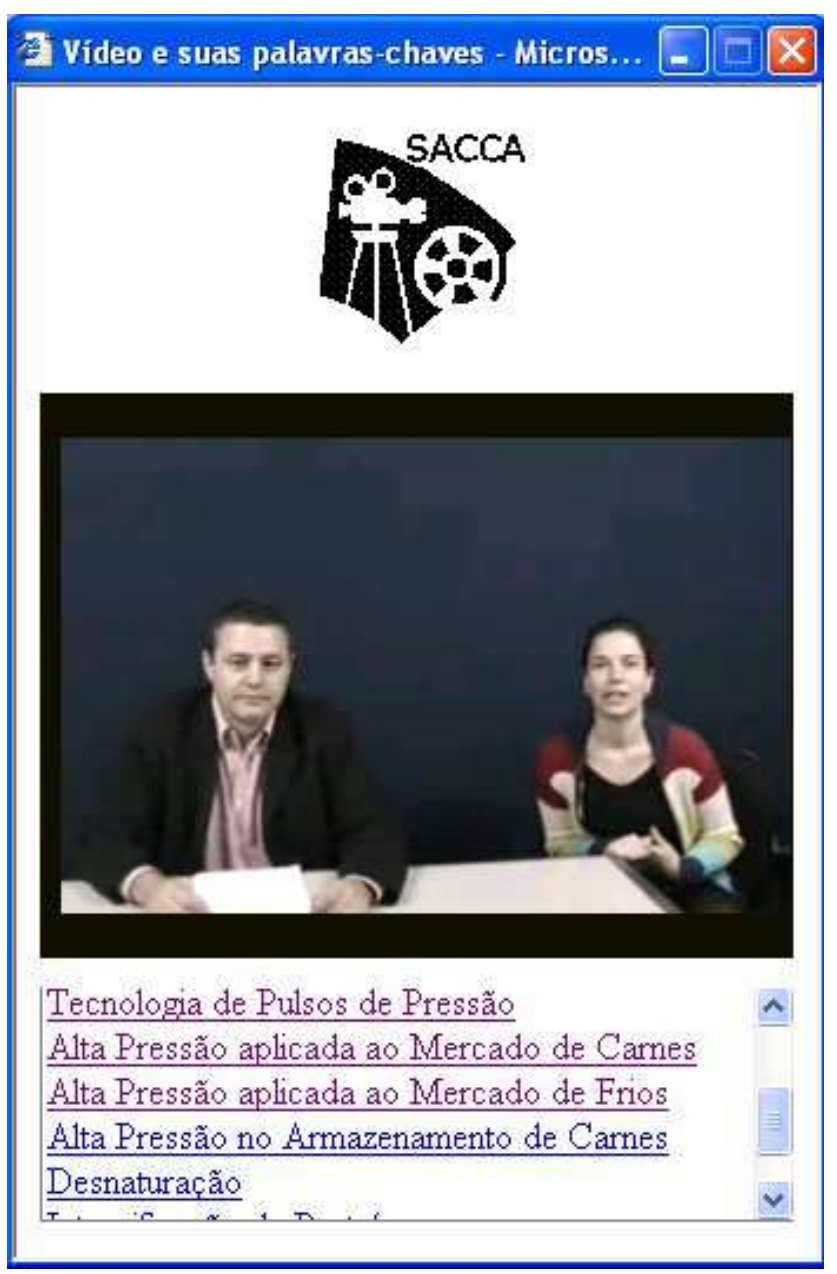

Figura 2 - Módulo Visualizador do SACCA

Um Módulo Visualizador foi projetado e está em fase final de implementação para ser integrado a estes dois sistemas, com vistas a permitir a exibição dos vídeos, a partir de momentos referenciados por um link (uma URL associada a um instante em que uma dada palavra chave é falada).

O usuário utilizará o CESTA como ponto de partida, pesquisando e navegando os diversos vídeos catalogados. Neste processo, o usuário poderá ver toda a descrição dos vídeos segundo as especificações do Learning Object Metadata do IEEE e também pesquisar por palavras-chave associadas ao conteúdo dos vídeos (cenas). Isto irá ocorrer consultando o banco de dados invertido, uma extensão dos dados do cesta, contendo todas as palavras chave gravadas no MPEG-7, o nome e a localização do arquivo de vídeo correspondente. A partir destes dados o sistema abre o arquivo MPEG 7 e mapeia todas as ocorrências da palavra chave dentro do vídeo, para mostrar ao usuário. Neste ponto o usuário então pode escolher qual o ponto exato que deseja assistir, ação que irá ocorrer através de um applet baseado no Java Media Player, alterado para tocar partes do vídeo a partir das descrições MPEG 7.

\subsection{Implementação do Projeto}


O módulo de exibição foi o ponto de partida do projeto e para este foi escolhida a utilização da linguagem Java para possibilitar a transcodificação de múltiplos formatos de mídia através da Internet, com total portabilidade e interoperabilidade.

Este sub-sistema foi implementado inicialmente com classes do Java Media Player, um subconjunto da API Java Media Framework (JMF), que permite que áudio, vídeo e outros tipos de mídia sejam adicionados em aplicações e applets desenvolvidos com tecnologia. O módulo foi implementado e testado com sucesso, mas apesar de totalmente funcional, a JMF se mostrou insuficiente, pois entre os formatos de mídia suportados não se incluiam nenhum dos principais formatos de vídeo streaming (Window Media, Real e Quicktime).

Buscou-se então outras alternativas baseadas em Java e em conjunto foram analisados qual seria a melhor alternativa de video streaming a ser utilizada. A tecnologia Real (Real Networks) já era de domínio do grupo, pois desde 1995 os vídeos disponiblizados em servidores de vídeo sob demanda ou transmitidos em tempo real utilizaram esta tecnologia. A tecnologia Windows Media, também é utilizada mas em menor escala. Mas visto que a indexação estaria utilizando o padrão MPEG 7, buscou-se também conhecer sobre o padrão mais atual de vídeos, desenvolvido pelo grupo MPEG da ISO, o MPEG 4.

O MPEG 4 é uma evolução dos padrões MPEG 1 e MPEG 2 (utilizado nos DVDs), através da contribuição de centenas de pesquisadores pelo mundo, sendo finalizado em $1998 \mathrm{em}$ padronizado em 2000. O MPEG 4 foi desenvolvido para disponibilizar vídeos com no mínimo a mesma qualidade do MPEG 2, mas em taxas de transmissão mais baixas e com arquivos de tamanho reduzido, possibilitando o streaming destes vídeos através da Internet. Apesar de ser focado em áudio e vídeo, o MPEG 4 também suporta objetos 3D e outros tipos de formatos de arquivos. Sua utilização em conjunto com o MPEG 7 é uma grande promessa na disponibilização de conteúdos na TV Digital.

Diante das características do MPEG 4 e principalmente por este ser um padrão de fato, diferentemente dos padrões Real e Windows Media, decidiu-se pela utilização deste como formato inicial de vídeos do SACCA. A escolha do MPEG 4 levou à escolha do Quicktime da Apple, visto que este foi a base para a constituição do padrão MPEG 4. Com isto o novo módulo player está sendo implementado baseado na API Quicktime for Java, uma API que permite a construção de aplicações multimídia como exibidores de streaming de áudio e vídeo, embutidas em applets Java baseados no Quicktime.

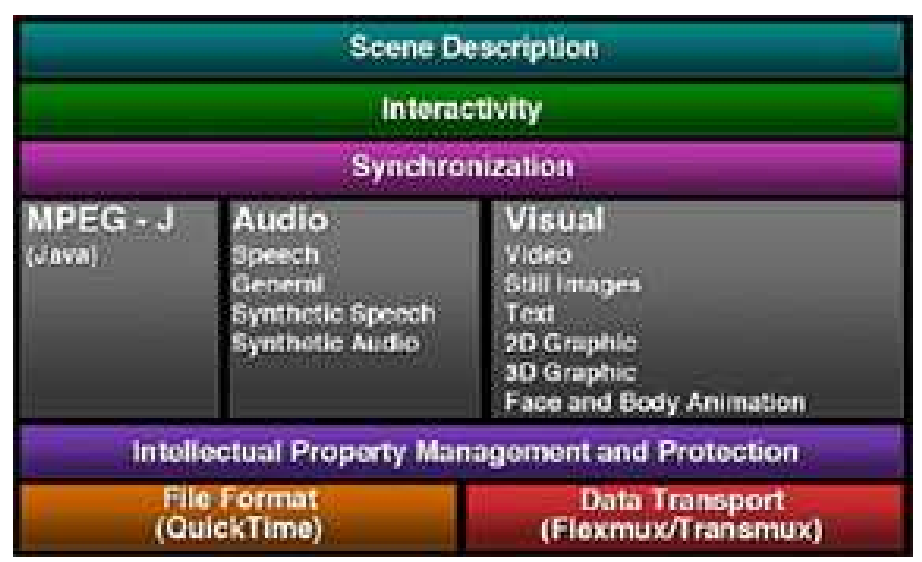

Figura 3 - Componentes do padrão MPEG 4

Para que se pudesse testar este novo módulo, baseado em vídeos MPEG 4, foi instalado um servidor de vídeo streaming Quicktime de código aberto, o Darwin Streaming Server (DWS). O DWS é uma versão de código aberto do Quicktime Streaming Server, que roda em servidores Windows, Unix e Linux. 
O desenvolvimento com esta nova API, no mostrou-se de inicio um pouco mais complexo do que no JMF, principalmente devido a uma documentação não tão abrangente por parte do Quicktime for Java em relação ao JMF e devido ao menor número de participantes nos fóruns de Quicktime for Java, principalmente no Brasil.

Atualmente, o protótipo do módulo de exibição está operacional e sendo testado. Apresentou bom desempenho na versão local mas quando utilizado através da Internet, o applet do Quicktime é bem mais pesado do que o gerado pelo JMF, o que demanda um certo tempo para sua carga na página. $\mathrm{O}$ esforço atual de implementação deste módulo, concentra-se em tentar refiná-lo com vistas a torná-lo mais enxuto e testar a sua interoperabilidade em navegadores e sistemas operacionais diferentes.

Com o módulo de exibição em versão beta, os esforços de implementação estão se concentrando na integração deste módulo com o Sistema CESTA, ampliando as formas de pesquisa dentro do Sistema Cesta, finalizando o Módulo Parser.

O Módulo Parser é um conjunto de scripts em PHP e JavaScript que lêem os arquivos XML do MPEG 7 no momento do upload via Sistema CESTA e alimentam o banco de dados do SACCA. Diferentemente do CESTA que utiliza o LDAP como banco de dados, no SACCA os dados extraídos do XML são armazenados em tabelas do Banco de Dados MySQL, escolhido devido a sua facilidade de uso, performance, portabilidade e principalmente pela sua flexibilidade nas formas de busca, características estas inerentes aos SGBDR (Sistemas Gerenciadores de Bancos de Dados Relacionais) atuais.

\section{Conclusões}

A utilização de vídeos educacionais digitalizados no processo de ensino e aprendizagem é cada vez mais uma ferramenta interessante, diante da crescente produção de vídeos educativos de qualidade. Também contribui para sua crescente importância o surgimento de padrões que auxiliam descrever e indexar os vídeos de forma padronizada, tais como o MPEG 7, possibilitando a busca e seleção de vídeos ou partes dele, integrados a conteúdos Web.

O Projeto SACCA utiliza estas tecnologias, integrando um repositório de conteúdos educacionais (CESTA), com conteúdos descritos em MPEG-7, possibilitando a busca, seleção e execução dos segmentos relacionados destes vídeos. A utilização de tecnologias padronizadas como o MPEG-7, Html, PHP e Java, alia grande eficiência a uma total portabilidade e interoperabilidade, características estas muito importantes em qualquer aplicação acadêmica de grande alcance. Buscase com este projeto oferecer a comunidade acadêmica uma ferramenta que auxilie alunos e educadores no enriquecimento de suas atividades acadêmicas.

\section{Referências}

Alphaworks. IBM MPEG 7 Annotation Tool. <http://www.alphaworks.ibm.com/tech/videoannex> Acesso em: 1 out.2004.

ANNODEX 2004 - http://www.annodex.net/index.html Acesso em 10 de março de 2005.

BURMARK, Lynell. Visual Literacy: Learn to See, See to Learn. 2004.

CESTA. Coletânea de Entidades de Suporte ao uso da Tecnologia na Aprendizagem. http://www.cinted.ufrgs.br/CESTA/. 2004. Acesso em 10 de março de 2005.

CHIARIGLIONE, Leonardo. The MPEG Home Page. Tocantis: s.ed., 2004. Disponível em: <http://www.chiariglione.org/mpeg/> Acesso em: 15 set. 2004.

FERRÉS, Joan . Pedagogia dos Meios Audiovisuais e Pedagogia com os Meios Audiovisuais. In SANCHO, Juana M. Para Uma Tecnologia Educacional; Org. Porto alegre: Art Med, 1998, p.127-155.

FERRÉS, Joan. Vídeo e educação. Porto Alegre: Artes Médicas, 1996. 
GT VD. GRUPO DE TRABALHO DE VÍDEO DIGITAL - RNP. Natal: s.ed., 2004. Disponível em : 〈http://girafa.natalnet.br/gtvd/index.jsp > Acesso em 10 out.2004.

HUNTER, Jane. MPEG 7 Behind de Scenes.D-Lib Magazine: . Vol 5 n.9. 1999. Disponível em < http://www.dlib.org/dlib/september99/hunter/09hunter.html> Acesso em 1 out.2004.

ISO/IEC. MPEG-7: Context and Objectives. ISO/IEC JTC1/SC29/

OROZCO, Guillermo. Professores e Meios de comunicação: Desafios, Estereótipos. Comunicação \& Educação, São Paulo, v.10, p.57-68.

SACCA. Sistema Automático de Catalogação de Conteúdo Audiovisual. http://www.cinted.ufrgs.br/SACCA/ Acesso em 11 de abril de 2005.

SANTAELLA, Lúcia. Palavra, imagem \& enigmas. Revista USP, n.16. dez./jan./fev.

SUN Java. Java Media Framework API. Disponível em < http://java.sun.com/products/javamedia/jmf/index.jsp> Acesso em 20 set.2004.

TAROUCO, L. M. R., Renato Luis de Souza Dutra, and Adriana Dallacosta. 2004. A Utilização da Indexação de Vídeos com MPEG-7 e sua Aplicação na Educação. In Renote Revista Novas Tecnologias na Educação, no. 1, 2:1-8. Porto Alegre - RS. 2003

Telecurso. http://www.telecurso2000.org.br/. Acesso em 11 de abril de 2005.

TV ESCOLA - O canal da Educação. Brasília: MEC, 2004. Disponível em: <http://www.mec.gov.br/seed/tvescola/default.shtm> Acesso em: 15 março. 2005.

VALA 2004. VALA - Virtual Adaptative Learning Architecture. http://www.vala.arizona.edu/ Acesso em 10 de março de 2005.

VEL - Virtual Entrepreneurship Lab. 2004 Acesso em 5 de março de 2005 http://wwwi5.informatik.rwthaachen.de/lehrstuhl/staff/klamma/Projects/virtual entrepreneurship lab.htm

W3C - 2004 http://www.w3.org/AudioVideo/ 